\title{
Borrowing to Survive: Investigating the Functioning of the Court of Justice of the EU through Comparative Law
}

\author{
Orlando Scarcello \\ Postdoctoral fellow, School of Law, LUISS Guido Carli University, Roma, Italy \\ oscarcello@luiss.it
}

\begin{abstract}
Leonardo Pierdominici's 'The Mimetic Evolution of the Court of Justice of the EU. A Comparative Law Perspective' is discussed here. I start considering the methodological tenets of the book, which investigates how the Court of Justice borrowed institutional settings from other jurisdictions and bent them to its needs throughout its history. The five substantive chapters of the book are then considered. Each chapter shows the impact of comparative law on one aspect of the functioning of the Court: the available actions, the appointment of judges, the transparency of decisions, the docket control mechanism, and the style of judgments. I end the review by suggesting a few missing topics that the book may have investigated.
\end{abstract}

\section{Keywords}

Court of Justice of the EU, mimetism, history of EU law, comparative law

Leonardo Pierdominici, The Mimetic Evolution of the Court of Justice of the EU. A Comparative Law Perspective, Palgrave MacMillan, Cham, 2020, 411 pages, eBook ISBN: 978-3-030-47864-3, Hardcover ISBN: 978-3-030-47863-6, Softcover ISBN: 978-3-030-47866-7

How could the Court of Justice of the EU, "tucked away in the fairyland Duchy of Luxembourg", become a major actor in the European process of (legal) integration and how can this role be maintained and enhanced in the future? Leonardo Pierdominici's book offers an answer to the riddle of the Court's success grounded in comparative law and, more specifically, in comparative institutional analysis. 
The academic literature surrounding the Court of Justice is massive, and finding a new perspective was surely not easy. ${ }^{1}$ Yet, the author succeeded in this task by advancing a thesis: the capacity of the Court to gain trust among officials, politicians, practitioners, and scholars must be explained by looking at its ability to borrow institutional solutions from various legal orders, both within and outside Europe, be them national or international orders, and to bend them to its functional needs. This ability to adapt to a sometimes-hostile environment by imitating the behavior of other institutions is summarized and expressed by the notion of the Court's mimetism. This is perhaps the upshot and the major finding of the entire book.

The thesis is sustained through methodological eclecticism, merging two venerable approaches in comparative law, functionalism and culturalism. While the former compares institutions and legal mechanisms from different jurisdictions by looking at their common goal, the telos they serve within a certain context, the latter aims at considering the different contexts, cultures, and histories for the comprehension of law as a social phenomenon. They are, in a sense, antithetical, as the former aims at discovering similarities beyond differences, while the latter focuses on differences despite apparent similarities. Pierdominici's book aims at taking advantage from both perspectives and combine them despite the apparent irreconcilability. How so? By highlighting how the Court regularly borrowed from various legal orders and how the borrowed solutions can only be fully grasped by understanding the context and legal culture they originally fitted in. However, once borrowed, they are also appropriated and bent to the needs of the Court, functionally adapted to the specificities of EU law. The mimetism of the Court can therefore only be understood by combining functionalism and culturalism as methods of comparative analysis (pp. 20-27).

A special role belongs in the book to historical analysis. To explain how the Court came to endorse specific legal solutions, Pierdominici often focuses on new historical studies in EU law. When engaging in such reconstructions, the author shows meticulous knowledge of both primary and secondary sources. The result is not only an extremely informative analysis of the role and evolution of the Court, but also a source of inspiration for further research in the next future.

1 E.g. see recently HORSLEY, The Court of Justice of the European Union as an Institutional Actor, Cambridge, 2018; PHELAN, Great Judgments of the European Court of Justice, Cambridge, 202O; SAURUgger and terpan, The Court of Justice of the European Union and the Politics of Law, London, 2016; NIC OLA and DAVIEs (eds.), EU Law Stories - Contextual and Critical Histories of European Jurisprudence, Cambridge, 2017. 
Given this complex methodological premises, the book is articulated in five substantive chapters.

We first find a historical analysis of the establishment of the Court of Justice. The author shows how already at its inception the Court was heavily influenced by existing models in the Member States of the Communities: the French judiciary shaped the administrative competences of the Court, the Italian mechanism of incidental review of constitutionality was a model for the preliminary ruling mechanism, the Dutch constitutional debate on direct effect and primacy of international law deeply influenced seminal decisions as Van gend en Loos and Costa. The Court, in other words, selectively borrowed doctrines useful to the need of the communities by looking at the existing legal frameworks in Member States.

The second substantive chapter focuses on the evolution of the selection of the Court's members. It starts with an extensive analysis of various methods of appointments of judges at the national level, with particular focus on the evolution of the American model from simple appointment to the mixed Missouri Plan in 1940. This allows showing how different methods of selection aim at balancing the need to preserve judges' independency with a certain level of accountability. Moving to comparative analysis of international fora, the need to preserve States' sovereign choices is added to the picture. The Court of Justice is then depicted as having strongly suggested the adoption of a "liberal" method of selection: looking again from a historical perspective at the role that members of the institution performed in the process of treaty reform, the author underlines how ECJ's members advocated for the model which was then successfully codified in Article 255 TFEU (pp. 120-133). This mechanism, introduced with the Lisbon Treaty, established a Panel of experts, including former members of the Court and of the General Court, to examine the proposed nominees, but the examination remains technical (knowledge of EU law and linguistic skills) in order to respect the States' sovereign appointment of judges.

Moving forth, we face the issue of the Court's deliberative process, its transparency and the additional authority it confers to the Court. While the esprit du temps is captured by noting how the process of even wider accessibility to internal acts of legal institutions has mostly spared the judiciary in the last decades, Pierdominici elaborates on the constitutional principle of transparency entrenched in Articles 1 TEU and 15 TFEU to justify wider transparency in the Court and notices that Luxemburg has to a certain extent already voluntarily disclosed a number of internal documents between 2012 and 2019 . These moves are conceptualized functionally as strategies to enhance the Court's perceived legitimacy and authority in the public sphere. The analysis of the debate on 
individual opinions, concurring and dissenting, deserves particular scrutiny, as the author sides against the introduction of such reform (pp. 168-175): while a plurality of judges' voices would be advisable in well-developed legal orders, the still young EU systems is still in need of a unitary voice, also in the light of the ECJ's "nomophylactic" function (a characteristic that is relentlessly recalled throughout the entire book). Too many voices and interpretations of EU law via concurring and dissenting opinions would politicize the role of the Court and generate confusion in national judges.

The fourth substantive chapter considers the issue of the Court's docket control of cases. While the existing literature has often looked at solutions adopted in other legal systems to diminish the growing workload of the Court (e.g. the American writ of certiorari mechanism), Pierdominici offers solid evidence of the still relatively underdeveloped status of EU law: the current workload of the Court, in other words, is still not heavy enough. Despite the growth in actions in Luxemburg, especially preliminary references, national courts do not refer enough to the Court of Justice (pp. 266-278). Thus, proposals to import docket control solutions do not sufficiently consider the specificities of EU law and must be discarded. Moreover, there is no evidence that cases like CILFIT, the closest thing to a judicial certiorari one finds in EU law, diminished in a significant manner the growth of actions. On the other hand, the Court has been able, according to the author, to use its own internal resources (rules of procedures, orders of inadmissibility, the General Court) as more neutral tools to handle the increasing workload, without compromising the direct connection with national courts through Article 267 TFEU.

The last substantive chapter is devoted to a classic topic in studies on the Court, namely the style of judgments of the Court. The historical-comparative perspective is again central in reconstructing the style of the decisions and its evolution. The "cryptic, Cartesian" style of argumentation in the origins is traced back to French legal formalism and logicism. An immediate connection between the initial laconism of the Court and the use of French as standard working language is made. However, the book does not stop to the surface and also carefully considers the alternative and more discursive styles of argumentation, mostly of German origin (e.g. the proportionality assessment), emerged in the judgments between the 196os and the 1980s. Finally, the extensive self-citation of precedents by the Court is traced back to the influence of common law jurisdictions and to the need to ensure guidance to national judges.

Overall, the book accomplishes its goal: it offers a picture of the evolution of the Court of Justice throughout the decades and examines the ability of the Court to borrow mechanisms and legal frameworks from other jurisdictions 
when necessary. At the same time, the author spots cases, like the docket control, in which the Court carefully avoided to import solutions which would not facilitate the specific goals of a supranational institution. This ability to internalize functional innovations and discard dis-functional ones is the essence of the Court's mimetism. The introduction of such concept is perhaps the major research finding in the book.

The large use of a careful methodology, mostly historical, allows the book to move beyond black letter analysis and properly investigate the evolution of the examined institutions. Nevertheless, one is left with a relatively unexplained selection of the various examined aspects of the Court. While the establishment of the Court, selection of judges, deliberation and transparency, docket control, and the style of judgments are all crucial characteristics of the Court (sometimes even topoi in the literature), one may wonder why other issues were not investigated. For instance, a systematic study regarding the introduction and functioning of the General Court and the dismissed Civil Service Tribunal could have been another worthy topic. The individual actions of annulment and the evolution of Article 263 TFEU might have been another. An in-depth study of the evolution of the Grand Chamber (and of its influence on the Court at large) yet another. Briefly, one may imagine various other aspects of the Court's institutional evolution to examine in a comparative perspective. Of course, the most straightforward answer here would be that no single book can be comprehensive enough to encompass all aspects in the evolution of the Court and that one can only focus on a selection of paradigmatic cases (as the authors explicitly says). But this is exactly why clearer selection criteria would have been useful to the reader. Criteria on the order of chapters are indeed provided (pp. $28 \mathrm{ff}$ ), but they do not always seem compelling (e.g. the analysis of the style of judgments may have perhaps followed immediately the chapter on deliberation and transparency). Also, while the discussion of the influence of external comparative models is extensive, less attention is reserved to the Court as an "exporter" of legal solutions, an issue worth considering in a future revision (or maybe in a separate book). Lastly, at times the reader can be puzzled by hasty shifts from descriptive analysis of the Court's evolution to plainly normative arguments regarding reforms of various mechanisms. This remark does not concern the merit of such proposals, which may be sometimes controversial (e.g. the dismissal of dissenting and concurring opinions in a moment in which a stronger legitimation for the Court would be needed may be debatable), but only the sometimes quick shift from the descriptive to the prescriptive in the book.

However, these last remarks remain largely marginal and easily amendable. Overall, the book is refreshing (especially in its method), well-written, and 
offers a modern, sophisticated, detailed analysis of the Court as an evolving institution. It studies the law as a social phenomenon and advances the field of comparative institutional analysis in a notable manner. Most importantly, it works as a terrific basis for future research questions and research projects: a must-read for comparative and EU lawyers working on institutional analysis of courts in Europe. 